\title{
Optimizing Accuracy and Computational Cost in Theoretical Squaramide Catalysis: the Henry Reaction
}

\author{
Juan V. Alegre-Requena ${ }^{[a]}$ Eugenia Marqués-López ${ }^{[a]}$ and Raquel P. Herrera*[a]
}

\begin{abstract}
This study represents the first example where the accuracy of different combinations of density functional theory (DFT) methods and basis sets has been compared in squaramide catalysis After an optimization process of the precision obtained and the computational time required in the computational calculations, highly precise results were achieved compared to the experimental outcomes while using the least amount of time as possible. Here, we have explored computationally and experimentally the mechanism of squaramide-catalyzed Henry reaction. This is a complex reaction of about 100 atoms and a great number of diverse non-covalent interactions. Moreover, this research is one of the scarce examples where the organocatalyst acts in a trifunctional manner and is the first investigation in which a trifunctional squaramide catalyst has been employed. Functional $\omega B 97 X-D$ showed the best results when used with different versions of the 6-311 basis sets, leading to highly accurate calculations of the outcomes of the Henry reaction using nine aldehydes with different structural characteristics. Furthermore, in these relatively large systems, the use of a split-valence triple-zeta basis set saves a large amount of time compared to using larger basis sets that are sometimes employed in organocatalytic studies, such as the TZV and Def2TZV basis set families.
\end{abstract}

\section{Introduction}

Evolution has shown us over millions of years how the development of highly effective biocatalysts is a process where catalysts gain efficiency and selectivity as catalytic systems become more and more complex. Currently, we are able to perform countless reactions with outcomes that until recently were not even imaginable due to, in part, the creation of complex catalytic systems that bind more efficiently and selectively to the substrates employed in reactions.

Normally in asymmetric organocatalysis, the non-covalent interactions between the catalysts and the substrates are key players in promoting the reactions ${ }^{[1]}$ As the complexity of these systems grows, the number of interactions between catalysts and substrates generally increases, making the study of reaction mechanisms more intriguing and challenging. In this field, squaramides are a good example of complex catalysts that are used to obtain high stereoselectivities through the formation of

[a] J. V. Alegre-Requena, Dr. E. Marqués-López, Dr. R. P. Herrera Laboratorio de Organocatálisis Asimétrica. Departamento de Química Orgánica

Instituto de Síntesis Química y Catálisis Homogénea (ISQCH)

CSIC-Universidad de Zaragoza

C/ Pedro Cerbuna 12, 50009 Zaragoza (Spain)

E-mail: raquelph@unizar.es

Supporting information for this article is given via a link at the end of the document.((Please delete this text if not appropriate)) numerous non-covalent interactions in chiral environments. ${ }^{[2]}$ Also, the complex conformational systems of these compounds, which normally contain large structures with functional groups that can adopt multiple conformations, ${ }^{[2 \mathrm{~b}, 3]}$ represent another challenge for those who study their catalytic mechanisms.

Moreover, with the increasing interest for the synthesis of more complex catalytic systems with a high organization grade and a multidentate activation to offer a cooperative effect resembling the role of enzymes, trifunctional organocatalysts have emerged as an interesting option. ${ }^{[4]}$ These multifunctional structures bearing multiple hydrogen bond donors and acceptors could facilitate the formation of more interactions in a synergic way and, thereby, significantly improve their catalytic activity. ${ }^{[5]}$

In this investigation, we explored the Henry reaction catalyzed by trifunctional squaramide 3 , since it represents a clear example of a complex and effective catalytic system (Scheme 1). In this system, a great number of non-covalent interactions are formed, including hydrogen bonds, $\pi$-oxygen, $\pi$-hydrogen and other kinds of weak interactions. ${ }^{[6]}$ In addition, this is a large system in which the catalyst-substrate complex contains around 100 atoms. The catalyst activates the reaction creating interactions with the substrates mainly through three different groups: an amino, a squaramido and a naphthyl group (trifunctional catalysis). All these interactions created between the catalyst and the substrates make the catalytic system very efficient to promote the process with a catalyst loading of only $0.25 \mathrm{~mol} \%$, which is the lowest amount employed for this reaction in organocatalysis.

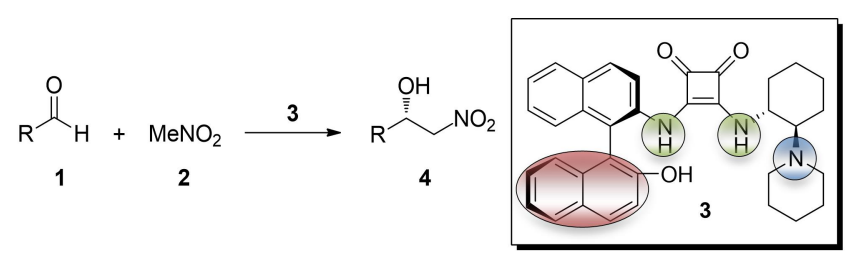

Scheme 1. Henry reaction catalyzed by trifunctional squaramide 3 .

In computational chemistry, squaramide catalysis is an area that has been scarcely developed and to date there are not many studies that have tackled this issue ${ }^{[2]}$ Furthermore, there are not any studies regarding the accuracy of different combinations of basis sets and methods compared to experimental results. Many times, relatively large basis sets are used to obtain reliable results; however, sometimes the amount of time required is prohibitive for studying these considerably large systems. Therefore, it is highly desirable to find computational approaches that provide accurate results while requiring the least amount of computational time as possible. This research could be crucial for the development of computational squaramide catalysis, an area in which researchers normally deal with catalyst-substrate complexes that contain large amounts of atoms. 


\section{Results and Discussion}

Before the mechanism was studied computationally, some experiments were done in order to collect useful information about this reaction. This experimental study included kinetic, kinetic isotope effect (KIE) and NMR experiments, as well as reactions using different catalysts and additives. We employed 4-cyanobenzaldehyde (1a) as the model aldehyde due to it is easy to handle and it does not contain appreciable amounts of its acid form. Since we have observed that the residual amounts of acid present in other aldehydes quench the Henry reactions catalyzed by squaramide 3 , due to the deactivation of the catalyst molecules caused by the protonation of their amino groups. Furthermore, we used always the same temperature in the experiments $\left(30.9^{\circ} \mathrm{C}\right)$, which was measured using a glycol solution in DMSO- $d_{6}$.

\section{NMR experiments. Catalyst-substrate interactions}

First, diverse nuclear magnetic resonance (NMR) experiments were performed in order to investigate how the different substrates of the reaction interacted with the squaramide catalyst. Since it was not possible to use $\mathrm{CD}_{3} \mathrm{NO}_{2}$ for these experiments because the reaction started right after the addition of aldehyde 1a, we chose $\mathrm{CD}_{3} \mathrm{CN}$ as the solvent. Even though the molecules adopt different conformations and ways of aggregation in $\mathrm{CD}_{3} \mathrm{CN}$ compared to those observed in $\mathrm{CD}_{3} \mathrm{NO}_{2}$, these studies brought a useful vision of the interactions formed in the catalyst-reagent complexes. At the same concentration of catalyst, different amounts of $\mathrm{MeNO}_{2}$ (2) and aldehyde 1a were added to study the resulting shifts in the catalyst's ${ }^{1} \mathrm{H}-\mathrm{NMR}$ signals. The results suggested that the formation of interactions was fast, since changes of the hydrogen signals of catalyst 3 were observed immediately after the addition of nitromethane (Figure 1) and aldehyde (Figure S2).

When 1a was added, the signals of the catalyst showed small shifts even when large amounts of 1a were used, probably due to the low proportion of molecules of $1 \mathbf{1 a}$ interacting with compound 3 (Figure S2). In contrast, when $\mathrm{MeNO}_{2}$ was added, the squaramide's peaks shifted considerably when one equivalent of $\mathrm{MeNO}_{2}$ was added and they did not shift further after subsequent additions (Figures 1 and S3). This suggests that the complex $\left[3-\mathrm{H}^{+}\right]\left[\mathrm{CH}_{2} \mathrm{NO}_{2}^{-}\right]$is the main species when one or more equivalents of $\mathrm{MeNO}_{2}$ are added and, therefore, it is the main species when $\mathrm{MeNO}_{2}$ is used as the solvent.

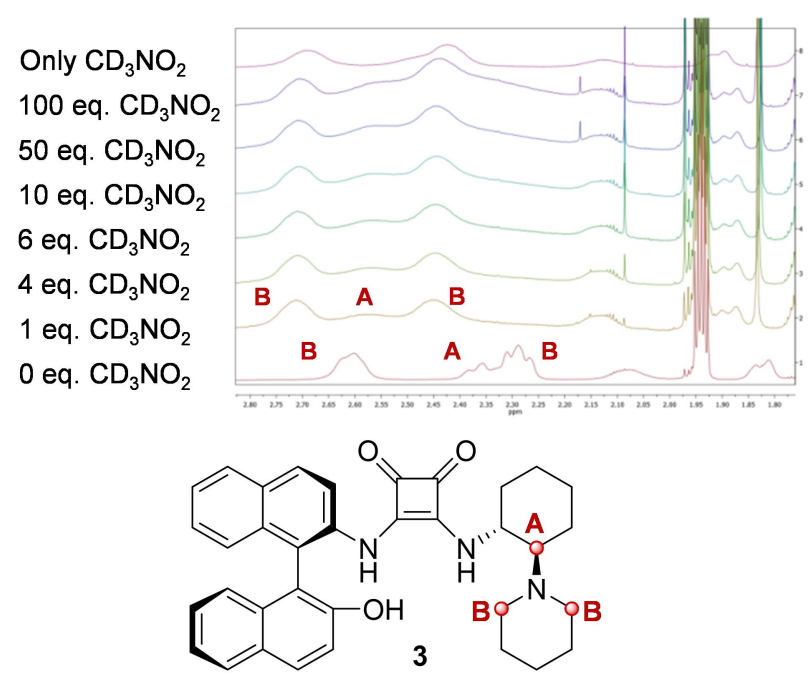

Figure 1. Aliphatic region of the ${ }^{1} \mathrm{H}-\mathrm{NMR}$ spectra of squaramide $3(0.01 \mathrm{mmol})$ in $\mathrm{CD}_{3} \mathrm{CN}(0.5 \mathrm{~mL})$ after the addition of different equivalents of $\mathrm{CD}_{3} \mathrm{NO}_{2}$ at 30.9 ${ }^{\circ} \mathrm{C}$.

\section{Retro-Henry reaction}

Furthermore, we studied whether or not the retro-Henry or other side reactions proceeded under the optimized conditions. For simplicity, the term retro-Henry reaction will include all the processes that transform the products (4) into the initial reagents (1 and 2) depicted in Scheme 1. For this study, we performed the Henry reaction with $1 \mathrm{a}$ at $-24{ }^{\circ} \mathrm{C}$. Under these conditions the corresponding product $4 \mathrm{a}$ is obtained with $80 \%$ enantiomeric excess. At $30.9^{\circ} \mathrm{C}$, the Henry reaction of $1 \mathrm{a}$ leads to the product 4a with an enantiomeric excess of $54 \%$ ee. Then, the enantiomeric excess of the product with $80 \%$ ee would change and progressively would become lower when product $4 \mathbf{a}$ is dissolved in a solution of $\mathrm{MeNO}_{2}$ containing catalyst 3 at 30.9 ${ }^{\circ} \mathrm{C}$.

The retro-Henry reaction was appreciable at $30.9{ }^{\circ} \mathrm{C}$, since the initial enantiomeric excess of the product changed from $80 \%$ to $58 \%$ ee over two days (Table 1 ). The results also suggested that retro-Henry reactions are much slower than Henry reactions: while Henry reactions are completed within a few hours at 30.9 ${ }^{\circ} \mathrm{C}$, the variations in the enantiomeric excess produced by the retro-Henry reaction required much longer times (48 hours for a variation from $80 \%$ to $58 \%$ ee). It is worth noting that the same enantiomeric excess $(52-54 \%$ ee) is observed in the Henry reaction of 1a over one day at $30.9^{\circ} \mathrm{C}$ (Table S1). This indicates that the enantiomeric excesses obtained are not significantly affected by other side reactions during the course of the Henry reactions.

Table 1. Changes in the enantiomeric excess values of product 4 a with $80 \%$ ee when it is dissolved in a solution of $\mathrm{MeNO}_{2}$ containing squaramide 3 at 30.9 ${ }^{\circ} \mathrm{C}$.

\begin{tabular}{ccc}
\hline $\mathrm{T}\left({ }^{\circ} \mathrm{C}\right)^{[a]}$ & Time $(\mathrm{h})$ & ee $(\%)^{[\mathrm{b}]}$ \\
\hline 30.9 & 0 & 80 (initial) \\
& 24 & 68 \\
& 48 & 58 \\
\hline
\end{tabular}

[a] Reaction conditions: Product 4a with $80 \%$ ee $(0.2 \mathrm{mmol}, 0.2 \mathrm{M})$ was added to a solution of squaramide $3(0.002 \mathrm{mmol}, 0.002 \mathrm{M})$ dissolved in 
$\mathrm{MeNO}_{2}(1 \mathrm{~mL})$ at $30.9{ }^{\circ} \mathrm{C}$. Then, after the corresponding time, an aliquot was extracted and the product was isolated by column chromatography. [b] Determined by chiral HPLC analysis using a Daicel Chiralpak IB column ( $n$-hexane/i-PrOH $=90: 10$, flow rate $1 \mathrm{~mL} \mathrm{~min}^{-1}, \lambda=243.5 \mathrm{~nm}$ )

All the information gathered from the previous studies suggested that the reaction pathways that form the global mechanism contain different reaction steps. The representation of the reaction steps for each individual pathway is depicted in Scheme 2. It is worth noting that in this representation, the term "Henry reaction" involves all the steps from Int1 to the final step where $\mathbf{4}$ separates from the catalyst. Analogously, the term "retro-Henry reaction" involves all the steps of the Henry reaction but in the opposite direction of the reaction.

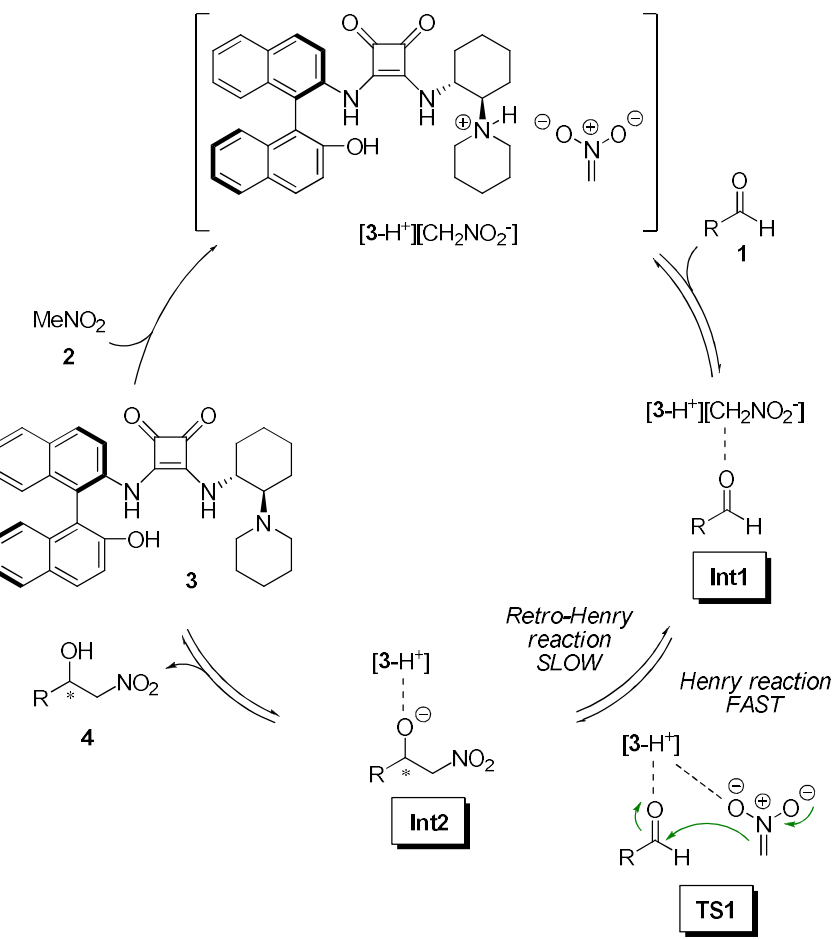

Scheme 2. Reaction steps of the individual reaction pathways of the Henry reaction studied.

\section{Orders of the Henry reaction}

In mechanistic studies, orders of reaction are very important since they give valuable hints about the amount of molecules of each type involved in the reaction mechanism. Using NMR experiments we calculated the orders of reaction for each component. The changes in aldehyde concentration (C) and $\operatorname{In}(\mathrm{C})$ over time showed that the order of reaction of aldehyde $1 \mathrm{a}$ was 1 in diverse reactions using different catalyst loadings and temperatures (Figures 2 and $\mathrm{S} 1$ ).
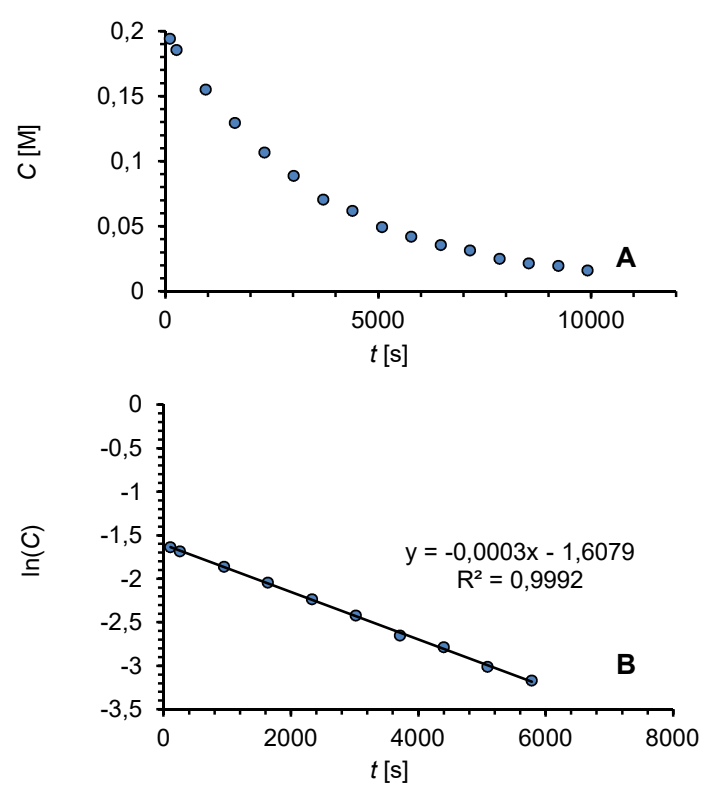

Figure 2. $C(A)$ and $\ln (C)(B)$ of aldehyde 1 a versus time at $30.9{ }^{\circ} \mathrm{C}$ and 2.5 $\mathrm{mol} \%$ of catalyst 3 .

In order to determine the order of reaction of catalyst $\mathbf{3}$, we employed the method of initial rates. ${ }^{[7]}$ These experiments indicated that squaramide 3 has a reaction order of 1 in this Henry reaction under different reaction conditions (Table 2).

Table 2. Initial rates at different temperatures and concentrations of squaramide 3.

\begin{tabular}{cccc}
\hline $\begin{array}{c}\text { Temperature } \\
\left({ }^{\circ} \mathrm{C}\right)\end{array}$ & $\begin{array}{c}\text { Catalyst loading } \\
(\mathrm{mol} \%)\end{array}$ & Initial rate $\left(\mathrm{M} \mathrm{s}^{-1}\right)$ & $\begin{array}{c}\text { Order of } \\
\text { reaction }\end{array}$ \\
\hline 30.9 & 2.5 & 0.00005603 & 1 \\
& 1 & 0.00002255 & \\
45.1 & 2.5 & 0.00012809 & 1 \\
\hline
\end{tabular}

The order of reaction of $\mathrm{MeNO}_{2}$ could not be determined by NMR experiments since it is the solvent of the reaction and its concentration remains practically constant during the course of the reaction. Changing the solvent of the reaction or modifying the concentration to study the order of reaction of $\mathrm{MeNO}_{2}$ might lead to erroneous results due to changes in the aggregation and conformation of the molecules involved in the reaction pathways (Figure S4). In this study, only the molecule of $\mathrm{MeNO}_{2}$ that carries out the attack on the aldehyde in the Henry reaction will be explicitly represented in the calculations, while the solvation effect of the other molecules of $\mathrm{MeNO}_{2}$ interacting with the system will be taken into account with the solvation model based on density (SMD) ${ }^{[8]}$ 


\section{Kinetic isotope effect (KIE)}

Moreover, we performed different KIE experiments using $\mathrm{CD}_{3} \mathrm{NO}_{2}$ to determine the rate-limiting reaction step (Table 3). The traditional mechanism determined for the Henry (nitroaldol) reaction ${ }^{[9,10]}$ consists in an initial deprotonation of $\mathrm{MeNO}_{2}$ followed by the attack of the forming nitronate to an aldehyde.

Table 3. KIE and reaction rate measurements of the Henry reaction at different temperatures.

\begin{tabular}{cccc}
\hline $\begin{array}{c}\text { Temperature } \\
\left({ }^{\circ} \mathrm{C}\right)\end{array}$ & $K_{\mathrm{H}}\left(\mathrm{s}^{-1}\right)^{[\mathrm{a}]}$ & $K_{\mathrm{D}}\left(\mathrm{s}^{-1}\right)^{[\mathrm{a}]}$ & $\mathrm{KIE}$ \\
\hline $30.9^{\circ} \mathrm{C}$ & 0.00025777 & 0.00047948 & $0.54^{[\mathrm{b}]}$ \\
$25.5^{\circ} \mathrm{C}$ & 0.00024300 & 0.00037263 & $0.65^{[\mathrm{c}]}$ \\
\hline
\end{tabular}

[a] Rate constants $K_{\mathrm{H}}$ were calculated following the "General Method for Measuring Orders of Reaction " section using $2.5 \mathrm{~mol} \%$ of catalyst that is detailed in the Experimental Section. Rate constants $K_{\mathrm{D}}$ were calculated following the same method but using only $\mathrm{CD}_{3} \mathrm{NO}_{2}$ as the solvent. [b] The $\mathrm{KIE}$ value is not exact, since the solvent used for determining $K_{H}$ contained $5 \%$ of $\mathrm{CD}_{3} \mathrm{NO}_{2}$. [c] This value was obtained using a mixture $\mathrm{CH}_{3} \mathrm{NO}_{2}: \mathrm{CD}_{3} \mathrm{NO}_{2}$ $(1: 9)$
In the KIE experiments, we observed inverse secondary KIE effects (Table 3), which is typical for reactions where the atom that performs the attack changes its hybridation from $\mathrm{sp}^{2}$ to $\mathrm{sp}^{3}$ (the $\mathrm{C}$ atom of $\mathrm{MeNO}_{2}$ in this reaction). ${ }^{[11]}$ This suggests that the rate-limiting reaction step is the $\mathrm{MeNO}_{2}$ attack on the aldehyde (TS1).

\section{Role of the $\mathrm{OH}$ group in squaramide 3}

Another important factor that was previously observed is that the $\mathrm{OH}$ group of squaramide 3 is not involved in a great extent in the mechanism. ${ }^{[6]}$ We performed some additional experiments using catalyst $\mathbf{5}$, which is identical to $\mathbf{3}$ except in that it has a $\mathrm{OMe}$ group instead of a $\mathrm{OH}$ group (Table 4). The results showed changes of only $2-8 \%$ yield and $2-5 \%$ ee when using catalyst 5 instead of catalyst 3 . The low variations observed in the outcomes of the reactions when using $\mathbf{3}$ and $\mathbf{5}$ suggest that the $\mathrm{OH}$ group is not involved significantly in the reaction mechanism.

Table 4. Henry reactions using $\mathbf{3}$ or $\mathbf{5}$ as the catalysts with various aldehydes and temperatures.

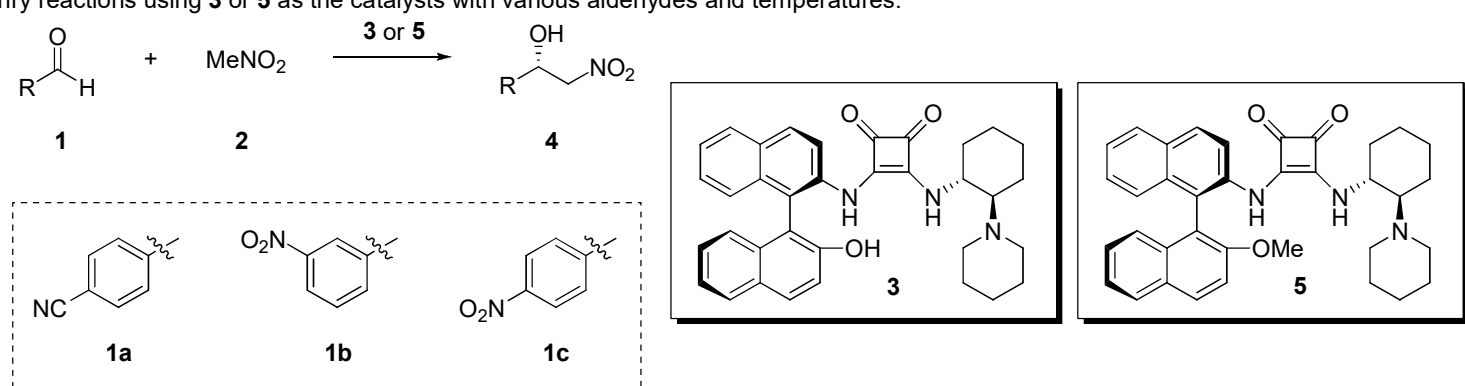

\begin{tabular}{|c|c|c|c|c|c|c|}
\hline Entry $^{[a]}$ & Catalyst & Aldehyde & $\mathrm{T}\left({ }^{\circ} \mathrm{C}\right)$ & Time $(h)$ & Yield (\%) & ee $(\%)^{[\mathrm{b}}$ \\
\hline 1 & 3 & $1 a$ & -24 & 19 & 56 & 78 \\
\hline 2 & 5 & $1 a$ & -24 & 19 & 48 & 74 \\
\hline 3 & 3 & $1 b$ & -24 & 17 & 91 & 94 \\
\hline 4 & 5 & $1 b$ & -24 & 17 & 93 & 92 \\
\hline 5 & 3 & 1c & -24 & 20 & 70 & 82 \\
\hline 6 & 5 & $1 \mathrm{c}$ & -24 & 20 & 63 & 77 \\
\hline 7 & 3 & $1 a$ & 30.9 & 14 & $>95$ & 54 \\
\hline 8 & 5 & $1 a$ & 30.9 & 14 & 90 & 54 \\
\hline
\end{tabular}

[a] Reaction conditions: Aldehyde $1(0.2 \mathrm{mmol}, 0.2 \mathrm{M})$ was added to a solution of squaramide 3 or $5(0.002 \mathrm{mmol}, 0.002 \mathrm{M})$ dissolved in $\mathrm{MeNO}$ (1 $\mathrm{mL})$ at the temperature indicated in the table. Then, after the corresponding reaction time, the products were purified by column chromatography. [b] Determined by chiral HPLC analysis.

\section{Role of water in the Henry reaction}

The presence of water molecules in the mechanism coming from the solvent was also investigated. Under the same reaction conditions, the addition of water did not affect the outcomes of the Henry reactions studied (Table 5). This suggests that water molecules from the solvent are not involved in the reaction mechanism. 
Table 5. Henry reactions of $\mathbf{1 a}$ and $\mathbf{1 b}$ in the presence of different amounts of water.

\begin{tabular}{|c|c|c|c|c|c|c|}
\hline \multirow{3}{*}{ Entry } & \multirow{2}{*}{$\begin{array}{r}+\quad \mathrm{MeNO} \\
2 \\
\end{array}$} & \multicolumn{3}{|c|}{3 (1 mol\%) } & \multicolumn{2}{|c|}{$\underline{\mathrm{OH}}$} \\
\hline & & & & & & \\
\hline & Conditions & Aldehyde & $\mathrm{T}\left({ }^{\circ} \mathrm{C}\right)$ & $\begin{array}{c}\text { Time } \\
\text { (h) }\end{array}$ & $\begin{array}{c}\text { Yield } \\
(\%)\end{array}$ & $\begin{array}{l}\mathrm{ee} \\
(\%)^{[\mathrm{b}]}\end{array}$ \\
\hline 1 & $\begin{array}{c}\mathrm{MeNO}_{2} \\
\text { anhydrous }\end{array}$ & $1 \mathrm{a}$ & -24 & 19 & 55 & 80 \\
\hline 2 & $\begin{array}{c}\mathrm{MeNO}_{2} \\
\text { anhydrous } \\
+11 \mu \mathrm{L} \mathrm{H}_{2} \mathrm{O}^{[\mathrm{a}]}\end{array}$ & $1 a$ & -24 & 19 & 47 & 82 \\
\hline 3 & $\begin{array}{c}\mathrm{MeNO}_{2} \\
\text { anhydrous }\end{array}$ & $1 b$ & -24 & 17 & 91 & 94 \\
\hline 4 & $\begin{array}{c}\mathrm{MeNO}_{2} \\
\text { anhydrous } \\
+11 \mu \mathrm{LH}_{2} \mathrm{O}^{[\mathrm{a}]}\end{array}$ & $1 b$ & -24 & 17 & 87 & 95 \\
\hline
\end{tabular}

[a] Addition of larger amounts of $\mathrm{H}_{2} \mathrm{O}$ resulted in heterogeneous reactions that led to the same results compared to those obtained when adding $11 \mu \mathrm{L}$ $\mathrm{H}_{2} \mathrm{O}$. Reaction conditions: Aldehyde $1(0.2 \mathrm{mmol}, 0.2 \mathrm{M})$ was added to a solution of squaramide $3(0.002 \mathrm{mmol}, 0.002 \mathrm{M})$ dissolved in $\mathrm{MeNO}_{2}(1 \mathrm{~mL})$ at $-24{ }^{\circ} \mathrm{C}$. Then, after the corresponding reaction time, the products were purified by column chromatography. [b] Determined by chiral HPLC analysis.

These initial experimental results guided the creation of a model for the system before starting the computational calculations. In summary, the experimental results suggested that: (1) squaramide 3 deprotonates $\mathrm{MeNO}_{2}$ in solution and interacts weakly with the aldehydes; (2) the reaction pathways follow the steps depicted in Scheme 2; (3) the order of reaction of the catalyst and aldehyde is $1 ;(4)$ the rate-limiting reaction step is the nitronate attack on the aldehydes; (5) the $\mathrm{OH}$ group of the catalyst is not involved significantly in the reaction; and (6) water molecules from the solvent does not interfere in the mechanism.

\section{Computational study of the mechanism}

With the information gathered in the experimental studies, we began to study the reaction mechanism, focusing on the nitronate attack on the aldehyde (rate limiting step) since it is the step that determines the stereoselectivity of the reactions. Initially, different systems were designed in which the three initial components of the reaction (protonated squaramide $\mathbf{3}$, deprotonated nitromethane and aldehyde 1a) interacted noncovalently. This led to a wide variety of possibilities, since the three molecules could interact through different functional groups and the catalyst could adopt many different conformations. In total, we found more than 50 different structures (using B3LYP/6-31G(d)) ${ }^{[12,13]}$ that showed relatively complex networks of hydrogen bonds and other non-covalent interactions, such as $\pi$-stacking and electrostatic interactions (Figure S5). Then, we analyzed these structures and selected those that could lead to the nitronate attack on the aldehyde while following the criteria established in the previous experimental exploration. Therefore, we discarded the structures that: (1) did not follow a pathway that connected them to any Henry reaction product; and (2) did not pass the experimental criteria (i.e., when the $\mathrm{OH}$ was significantly involved in the mechanism).

After this thorough preliminary study, we found seven pathways using B3LYP/6-31G(d) and $\omega B$ 97X-D/6-31G(d) ${ }^{[14]}$ (Figure 3). It is useful to note that pathways P1, P3 and P6 are equivalent to pathways P2, P4 and P7, respectively, with the only difference being the direction of the $\mathrm{OH}$ group. The direction of the $\mathrm{OH}$ group of the naphthyl moiety was an important factor at the beginning of this study since the changes of the position of this group affects the energy of each pathway in a different way. As stated above, we focused on the rate limiting step (TS1) because this step determines the stereoselectivity of the reactions. 


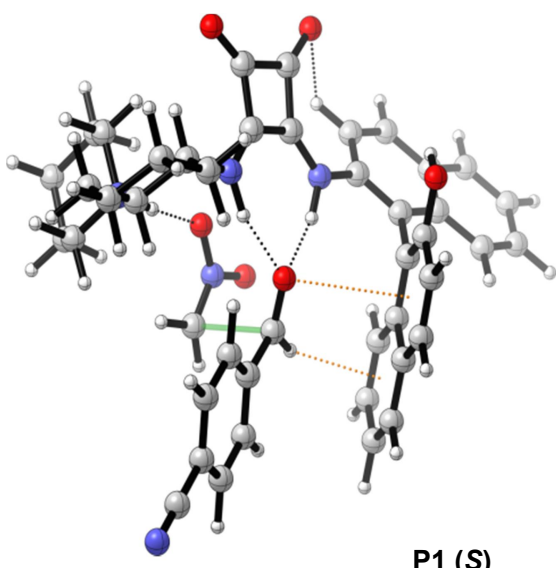

P1 (S)
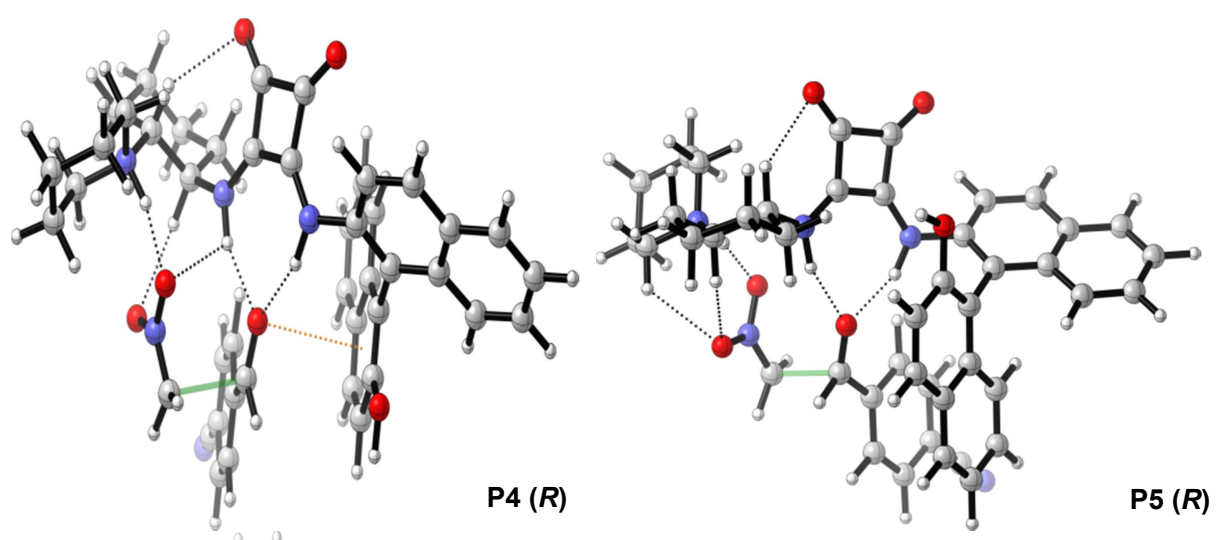
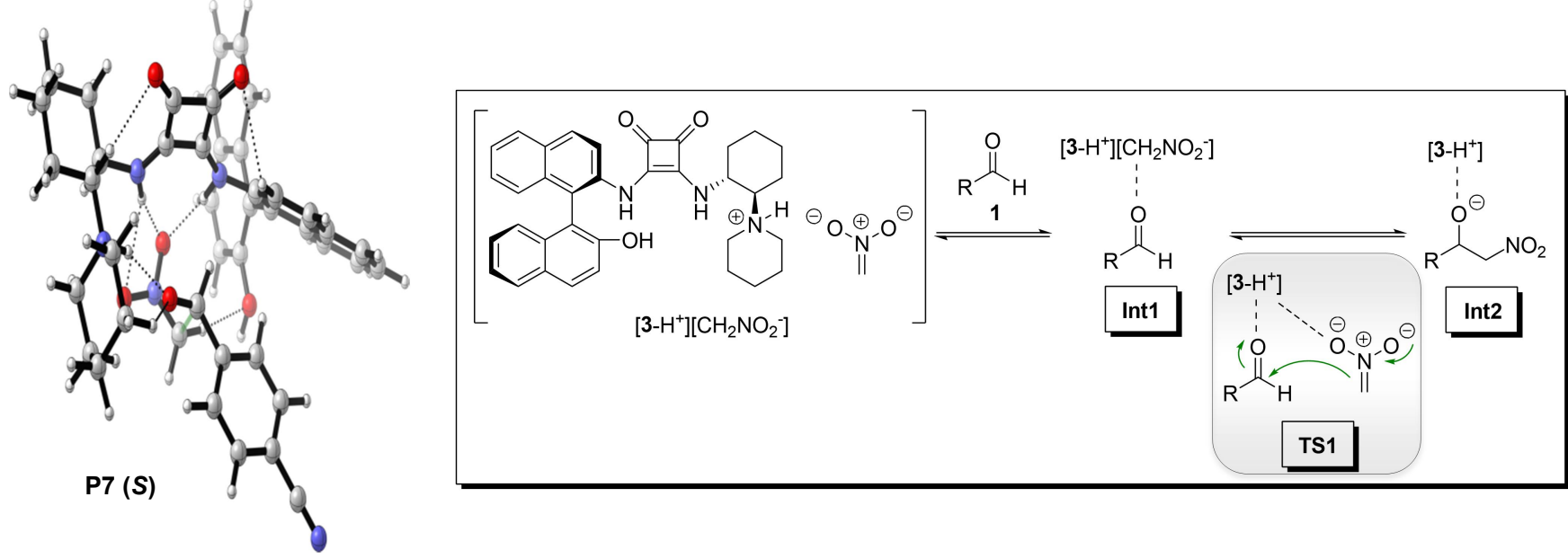

Figure 3. Tridimensional representations of TS1 of reaction pathways P1 to P7 (with the absolute configuration of the product derived from each pathway), using $\omega \mathrm{B} 97 \mathrm{X}-\mathrm{D} / 6-31 \mathrm{G}(\mathrm{d})\left(\mathrm{SMD}=\mathrm{MeNO}_{2}\right)$. Black dotted lines represent hydrogen bonds, orange dotted lines represent $\pi$-interactions and the semi-transparent green bonds represent the attack of the nitronate on aldehyde 1a. For a more detailed representation of each reaction pathway, see Figure S6 in the ESI.

The difference in the results between the two methods employed to study the seven pathways was considerable. First, B3LYP did not lead to product $\mathbf{4 a}$ with the absolute configuration observed in the experiments (Table 6). This was to be expected as this functional does not perform very well in systems with noncovalent interactions. ${ }^{[15]}$ On the other hand, functional $\omega B 97 X-D$ worked considerably well. It showed the formation of the correct enantiomer and presented an accurate value of enantiomeric excess at $30.9{ }^{\circ} \mathrm{C} \quad(51 \%$ ee $\quad$ [calculated] vs $54 \%$ ee [experimental]). 
Table 6. Relative $\mathrm{G}(\mathrm{kcal} / \mathrm{mol})$ of TS1 employing aldehyde $1 \mathrm{a}$, nitromethane and 3 as the catalyst along with their probability at $30.9{ }^{\circ} \mathrm{C}$.

\begin{tabular}{|c|c|c|c|c|c|}
\hline \multicolumn{3}{|c|}{ B3LYP/6-31G(d)(SMD= $\left.\mathrm{MeNO}_{2}\right)$} & \multicolumn{3}{|c|}{$\omega B 97 X-D / 6-31 G(d)\left(S M D=M^{2} N_{2}\right)$} \\
\hline Pathway & $\begin{array}{l}\text { Relative G of TS1 } \\
\quad(\mathrm{kcal} / \mathrm{mol})\end{array}$ & Probability $(\%)^{[\mathrm{a}]}$ & Pathway & $\begin{array}{l}\text { Relative G of TS1 } \\
\qquad(\mathrm{kcal} / \mathrm{mol})\end{array}$ & Probability $(\%)^{[\mathrm{a}]}$ \\
\hline P1 & -1.02 & $7.9(S)$ & P1 & -4.13 & $71.8(S)$ \\
\hline P2 & -0.55 & $3.6(S)$ & P2 & -2.21 & $3.0(S)$ \\
\hline P3 & -2.34 & $70.3(R)$ & P3 & -3.40 & $21.5(R)$ \\
\hline P4 & -1.29 & $12.4(R)$ & P4 & -1.92 & $1.9(R)$ \\
\hline P5 & -0.32 & $2.5(R)$ & P5 & -1.48 & $0.9(R)$ \\
\hline P6 & -0.13 & $1.8(S)$ & P6 & 0.00 & $<0.1(S)$ \\
\hline P7 & 0.00 & $1.4(S)$ & P7 & -1.49 & $0.9(S)$ \\
\hline \multicolumn{3}{|c|}{$\begin{array}{c}\text { Calculated ee (using all the pathways) } \\
\text { Experimental ee }=54 \%\end{array}$} & \multicolumn{3}{|c|}{$\begin{array}{c}\text { Calculated ee (using all the pathways) }=51 \% \\
\text { Calculated ee (using only P1 and } \boldsymbol{P} 3)=50 \% \\
\text { Experimental ee }=54 \%\end{array}$} \\
\hline
\end{tabular}

[a] Probabilities were calculated using Maxwell-Boltzmann statistics (see the ESI for more information).

Pathways $\mathbf{P} 1$ and $\mathbf{P} 3$ showed the two most favorable TS1 steps when using $\omega B 97 X-D$, which represented $93.3 \% \quad(71.8 \%$ P1(TS1) and 21.5\% P3(TS1)) of the global results (Table 6). The calculated enantiomeric excesses obtained using only these two pathways are very similar to those obtained using the seven pathways. This was also observed in later studies when using other aldehydes and, therefore, only $\mathbf{P} \mathbf{1}$ and $\mathbf{P} \mathbf{3}$ were taken into account to calculate the enantioselectivities. This is a timesaving approach that greatly reduces the amount of data involved while generating only low variations in the results obtained.

In order to find a reliable computational approach to study this squaramide-catalyzed reaction, it is highly desirable to use combinations of functionals and basis sets that: (1) lead to the correct absolute configuration of the products using a wide variety of substrates; (2) have small error margins; and (3) require as little time as possible. Different tests were conducted to determine the accuracy of diverse computational approaches employed for studying the Henry reactions. First, the difference of Gibbs free energy (G) between the TS1 of pathways P1 and P3 $\left(\Delta \Delta G^{\ddagger}\right)$ was calculated for Henry reactions using diverse para substituted aldehydes, which included atoms from different rows in the periodic table such as $\mathrm{Cl}$ and $\mathrm{Br}$, and the outcomes were compared to the experimental results. Aldehydes with substituents in the meta position and heterocycles were also employed in order to broaden the scope of this aldehyde computational screening. In these cases, four pathways (P1(A), P1(B), P3(A) and P3(B)) needed to be taken into account in the calculations since the substituent can be located in two different positions that have different $\mathrm{G}$ (Figure 4).
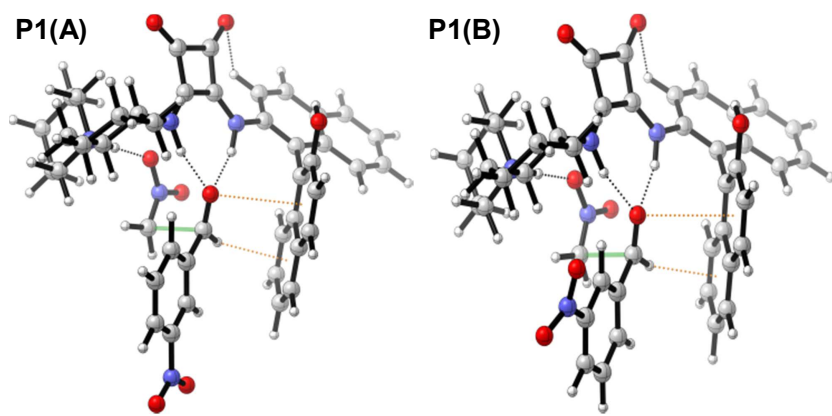

Figure 4. Example of the two different positions that the $\mathrm{NO}_{2}$ group adopts in TS1 of $\mathbf{P} 1$ when using aldehyde $\mathbf{1 b}\left(3-\mathrm{NO}_{2}\right)$

The computational approaches explored in this study included the first two functionals previously mentioned and additional functionals that included different dispersion corrections, such as M06-2X ${ }^{[16]}$ and B3LYP-D3(BJ). ${ }^{[17]}$ At first, these functionals were employed with the $6-31 \mathrm{G}(\mathrm{d})$ basis set since this basis set showed good results in combination with the wB97X-D functional. Also, another commonly used strategy was evaluated, in which single point energy calculations are performed employing geometries optimized at a lower level of theory, using the $G$ correction from the approach used in the optimization process (single-point strategies). Testing different methods is vital in this investigation since, as seen in Figure 5, the energies of the different reaction steps varies in a great extent when employing different methods to study these systems. ${ }^{[18]}$ Depending on the functional used, the results showed different relative energies in Int1, TS1 and Int2, which strongly affects the trajectories of the reaction pathways and the calculated enantiomeric excesses. 

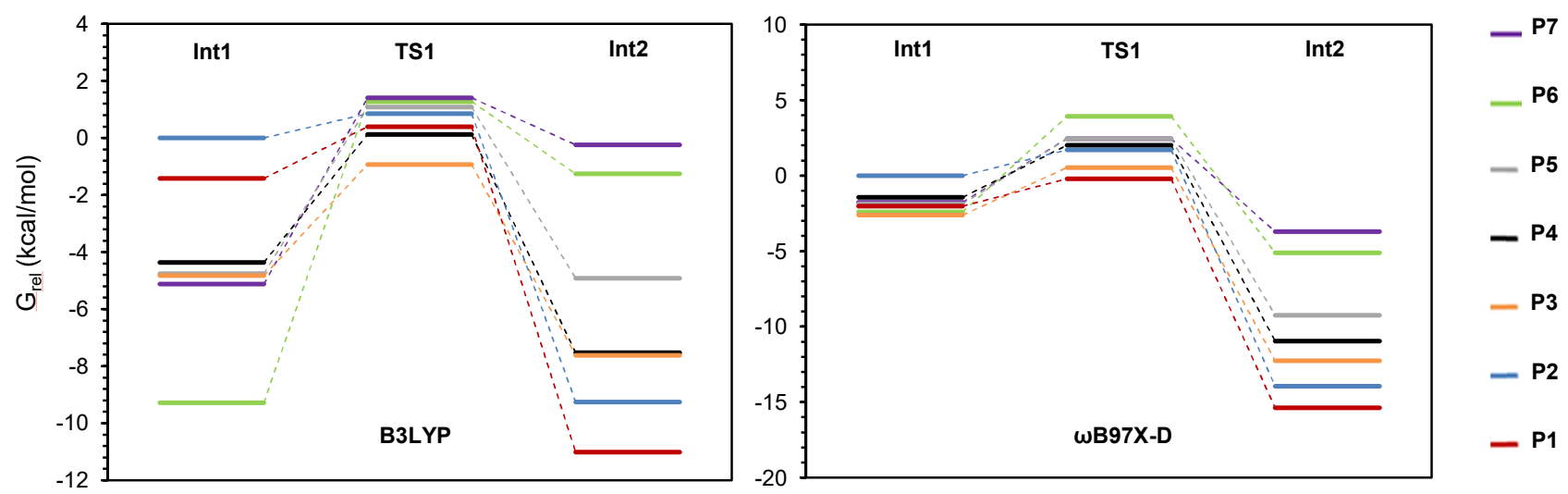

Figure 5. Representation of relative $\mathrm{G}$ (in kcal/mol) of Int1, TS1 and Int2 of the different reaction pathways (aldehyde $1 \mathrm{a}$, nitromethane and catalyst $\mathbf{3}$ at $30.9{ }^{\circ} \mathrm{C}$ ), using B3LYP/6-31G(d)(SMD=MeNO$\left.{ }_{2}\right)$ and $\omega B 97 X-D / 6-31 G(d)\left(S M D=M_{e N O}\right)$.

The results in the computational tests using different aldehydes were quite different depending on the functional employed. B3LYP led to the wrong absolute configuration of the products in four out of five aldehydes studied (1a, 1d, 1f and $\mathbf{1 g}$ ) and could not find the TS1 of 1c (Table 7). Also, M06-2X calculated the wrong enantioselectivity in five out of six reactions $(\mathbf{1 a}, \mathbf{1 c}, \mathbf{1 d}$, 1f and $\mathbf{1 g}$ ). This is probably due to the basis sets employed in the energy calculation, as when the energy was obtained using considerably larger basis sets the correct absolute configurations were observed (single-point strategies, ${ }^{[19]}$ Table S2). B3LYP-D3 did not lead to good results either, since there were various reactions in which the TS1 could not be found in
P1 (1a and 1c), even when larger Pople's basis sets, such as 6$311 \mathrm{G}(\mathrm{d}),{ }^{[20]}$ and basis sets from a different type, such as Def2$\mathrm{SVP}^{[21]}$ and cc-pVDZ, ${ }^{[22]}$ were employed (Figure S7). On the contrary, $\omega \mathrm{B} 97 \mathrm{X}-\mathrm{D}$ performs reasonably well taking into account that $6-31 \mathrm{G}(\mathrm{d})$ is a relatively small basis set. This method is able to find all the TS1 and it calculates the correct enantioselectivity in seven out of nine reactions (1a-c and 1f-1i) with absolute errors smaller than $1 \mathrm{kcal} / \mathrm{mol}$ in six of these examples $(\mathbf{1 a}-\mathbf{c}, \mathbf{1 f}$, $1 \mathrm{~h}$ and $\mathbf{1 i}$ ), which is generally considered to be within "chemical accuracy" in computational chemistry. Then, we further investigated the combination of $\omega B 97 X-D$ with different basis sets.

Table 7. $\Delta \Delta \mathrm{G}^{\ddagger}$ and errors (in $\mathrm{kcal} / \mathrm{mol}$ ) of diverse Henry reactions catalyzed by 3 using different functionals with the $6-31 \mathrm{G}(\mathrm{d})$ basis set and the SMD using $\mathrm{MeNO}_{2}$ as the solvent.
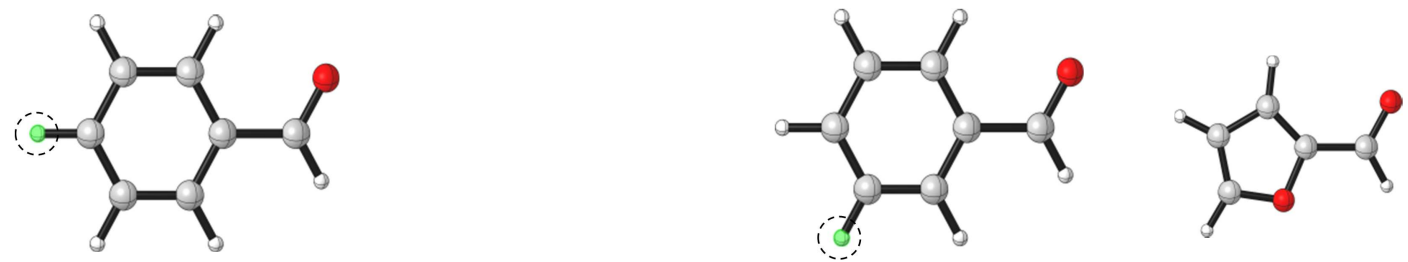

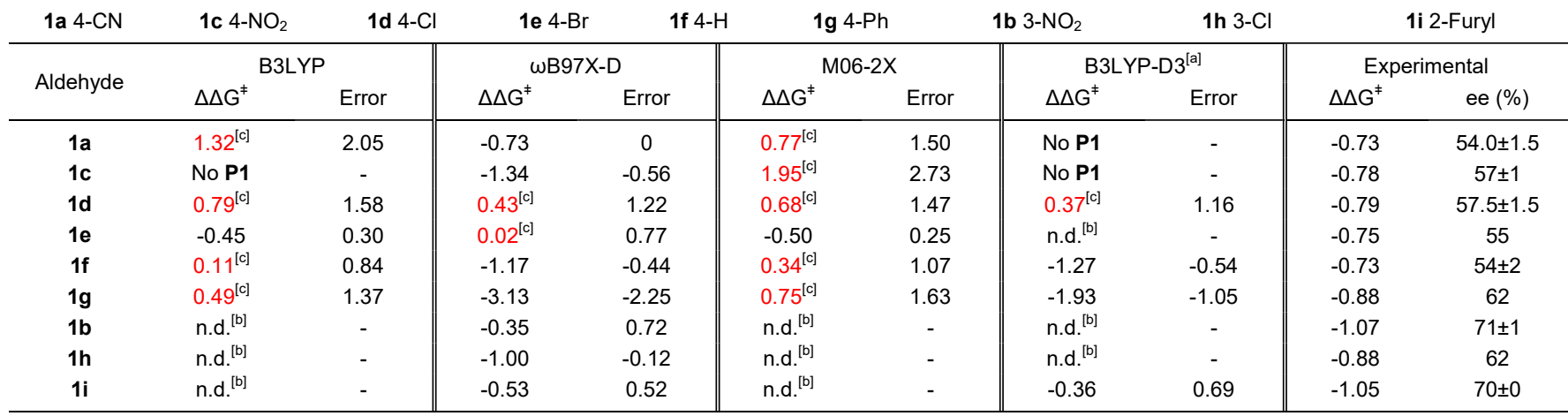

[a] In many cases, two imaginary frequencies existed in the TS1 calculations using B3LYP-D3, one corresponding to the transition state and one extra imaginary frequency. As an approximation, the additional imaginary frequencies were inverted into frequencies with positive values in the $\mathrm{G}$ calculations of these TS1 as seen previously. ${ }^{[23]}[\mathrm{b}]$ n.d. $=$ not determined. [c] Positive $\Delta \Delta \mathrm{G}^{\ddagger}$ values are represented in red and correspond to calculations that led to the opposite absolute configuration of the product compared to experimental results. $\Delta \Delta \mathrm{G}^{\ddagger}$ is the difference of $\mathrm{G}$ between the TS1 of pathways $\mathrm{P} 1$ and $\mathbf{P} 3$.

Although the $\omega B 97 X-D / 6-31 G(d)$ approach normally led to good results, it showed a significant drawback: this combination did not calculate the correct absolute configuration in two out of nine reactions (1d and 1e). At this point, we tried to improve these outcomes by applying different variations to this $\omega B 97 X-D / 6-$ $31 \mathrm{G}$ approach (ultrafine (UF) grid, hindered rotor correction, ${ }^{[24]}$ 
counterpoise (CP) corrections ${ }^{[25]}$ and Truhlar's and Grimme's quasiharmonic approximations (QHAs, also called quasiRRHOs). ${ }^{[26]}$ The results showed that a considerable increase in the precision is achieved when UF grids and QHA were applied, since (1) $\Delta \Delta G^{\ddagger}$ mean absolute errors (MAEs) are lower; (2) they more frequently calculate the correct absolute configurations; and (3) they more often show $\Delta \Delta G^{\ddagger}$ with margin errors below 1 $\mathrm{kcal} / \mathrm{mol}$ (Table 8, entries 1-6). The type of QHA employed is not relevant in this study, since the accuracy of the calculations was similar when using Truhlar's and Grimme's approach. On the other hand, the use of counterpoise and hindered rotor corrections did not lead to any considerable improvements in comparison with the initial approach (Table S3). 
Table 8. Accuracy in the calculated enantioselectivity of different computational approaches employed to study Henry reactions between aldehydes 1 a-i and $\mathrm{MeNO}_{2}$ using 3 as the catalyst. All the methods include the SMD using $\mathrm{MeNO}_{2}$ as the solvent.
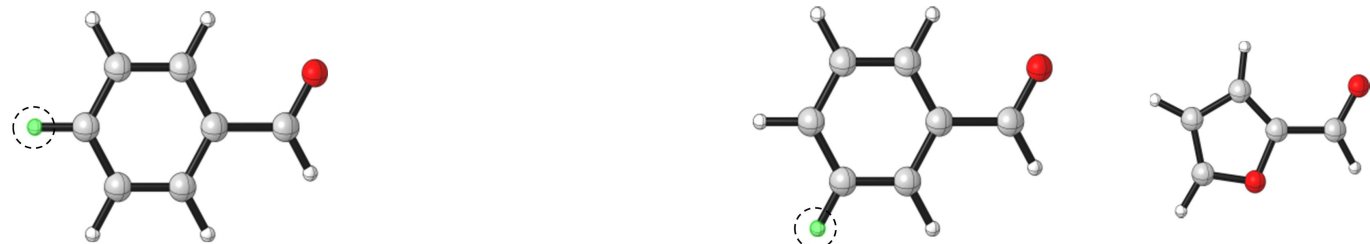

\begin{tabular}{|c|c|c|c|c|c|c|c|c|c|c|c|c|c|c|c|c|c|c|c|c|}
\hline \multirow{3}{*}{$\frac{1 \mathrm{a} 4}{\text { Entry }}$} & \multirow[b]{3}{*}{ Computational approach } & \multicolumn{4}{|c|}{1 e 4-Br } & \multicolumn{2}{|c|}{ 1f $4-\mathrm{H}$} & \multicolumn{3}{|c|}{$1 \mathrm{~g} \mathrm{4-Ph}$} & \multicolumn{4}{|c|}{ 1b $3-\mathrm{NO}_{2}$} & \multicolumn{4}{|c|}{ 1h $3-\mathrm{Cl}$} & \multicolumn{2}{|c|}{ 1i 2-Furyl } \\
\hline & & \multicolumn{9}{|c|}{ Correct absolute configuration ${ }^{[a]}$} & \multicolumn{9}{|c|}{$\Delta \Delta \mathrm{G}^{\ddagger}$ error within $\pm 1 \mathrm{kcal} / \mathrm{mol}^{[\mathrm{a}, \mathrm{b}]}$} & \multirow{2}{*}{$\begin{array}{l}\Delta \Delta \mathrm{G}^{\ddagger} \mathrm{MAE} \\
(\mathrm{kcal} / \mathrm{mol})^{[\mathrm{b}]}\end{array}$} \\
\hline & & $1 a$ & 1c & $1 d$ & $1 e$ & $1 f$ & $1 \mathrm{~g}$ & $1 \mathrm{~b}$ & $1 \mathrm{~h}$ & 1i & $1 a$ & 1c & 1d & $1 e$ & $1 f$ & $1 \mathrm{~g}$ & $1 b$ & $1 \mathrm{~h}$ & $1 \mathrm{i}$ & \\
\hline \multirow{2}{*}{1} & \multirow{2}{*}{$\omega B 97 X-D / 6-31 G(d)$} & \multicolumn{9}{|c|}{7 out of 9} & \multicolumn{9}{|c|}{6 out of 9} & \multirow{2}{*}{0.73} \\
\hline & & ه & $ه$ & 0 & 0 & ه & ه & $\varnothing$ & 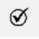 & $ه$ & $ه$ & $ه$ & 0 & 0 & $ه$ & 0 & $ه$ & $ه$ & $\varnothing$ & \\
\hline \multirow{2}{*}{2} & \multirow{2}{*}{$\begin{array}{c}\omega \mathrm{B} 97 X-\mathrm{D} / 6-31 \mathrm{G}(\mathrm{d})-\mathrm{QHA} \\
\text { Truhlar }\end{array}$} & \multicolumn{9}{|c|}{8 out of 9} & & & & & ut o & & & & & \\
\hline & & $ه$ & $ه$ & 0 & $ه$ & 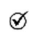 & $ه$ & $ه$ & $\otimes$ & $ه$ & $ه$ & $ه$ & 0 & 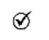 & $\varnothing$ & $\varnothing$ & $ه$ & $\varnothing$ & $\varnothing$ & 0.42 \\
\hline 3 & $\omega B 97 X-D / 6-31 G(d)-Q H A$ & & & & & ut 0 & & & & & & & & & ut 0 & & & & & 053 \\
\hline J & Grimme & $ه$ & $ه$ & 0 & ه & ه & ه & $ه$ & 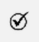 & $ه$ & $\varnothing$ & $ه$ & 0 & 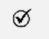 & $ه$ & $\mathrm{O}$ & $ه$ & $ه$ & $ه$ & 0.00 \\
\hline 4 & $\omega B 97 X-D / 6-31 G(d)-U F$ & & & & & ut o & & & & & & & & & ut o & & & & & 040 \\
\hline & grid & $\varnothing$ & $\mathrm{O}$ & 0 & $\varnothing$ & $ه$ & $ه$ & $\varnothing$ & 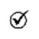 & $\varnothing$ & $\varnothing$ & 0 & 0 & $\varnothing$ & $ه$ & $\varnothing$ & $\varnothing$ & $ه$ & $\varnothing$ & 0.40 \\
\hline 5 & $\omega B 97 X-D / 6-31 G(d)-U F$ & & & & & ut 0 & & & & & & & & & ut o & & & & & 013 \\
\hline 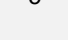 & grid - QHA Truhlar & $\varnothing$ & 0 & $\varnothing$ & 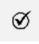 & $\varnothing$ & d & ه & 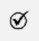 & $ه$ & $ه$ & 0 & 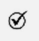 & $\varnothing$ & $\varnothing$ & $\varnothing$ & $ه$ & $\varnothing$ & $\varnothing$ & 0.40 \\
\hline 6 & $\omega B 97 X-D / 6-31 G(d)-U F$ & & & & & ut 0 & & & & & & & & & ut 0 & & & & & 011 \\
\hline 0 & grid - QHA Grimme & $ه$ & 0 & $\varnothing$ & 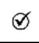 & $\varnothing$ & $ه$ & $ه$ & $\theta$ & $ه$ & $\varnothing$ & 0 & $\theta$ & $\varnothing$ & $\varnothing$ & $\varnothing$ & $\varnothing$ & $\varnothing$ & $\theta$ & 0.44 \\
\hline 7 & (1)R97X-D/6 $311 \mathrm{~g}$ & & & & & ut 0 & & & & & & & & & ut o & & & & & 106 \\
\hline$r$ & (aD21 & $\varnothing$ & $\varnothing$ & $\varnothing$ & $\varnothing$ & $\varnothing$ & $ه$ & $ه$ & 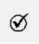 & $ه$ & $ه$ & 0 & 0 & 0 & 0 & 0 & $\varnothing$ & $\varnothing$ & $\varnothing$ & 1.00 \\
\hline 8 & $\omega B 97 X-D / 6-311 G(d)$ QHA & & & & & ut o & & & & & & & & & ut 0 & & & & & 067 \\
\hline 0 & Truhlar & $ه$ & $ه$ & $\varnothing$ & 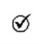 & $\varnothing$ & $ه$ & $ه$ & $\theta$ & $\varnothing$ & $\varnothing$ & $\varnothing$ & 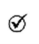 & $\varnothing$ & $\varnothing$ & 0 & $\varnothing$ & $\varnothing$ & $\varnothing$ & 0.01 \\
\hline 0 & $\omega B 97 X-D / 6-311 G(d)$ QHA & & & & & ut 0 & & & & & & & & & ut 0 & & & & & 0 \\
\hline y & Grimme & $ه$ & $ه$ & $\varnothing$ & $\varnothing$ & $\varnothing$ & 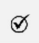 & $ه$ & $\varnothing$ & $\varnothing$ & $\varnothing$ & $ه$ & 0 & 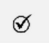 & 0 & 0 & $\varnothing$ & $ه$ & $\varnothing$ & 0.82 \\
\hline 10 & $\omega B 97 X-D / 6-311 G(d)-$ UF & & & & & ut o & & & & & & & & & ut 0 & & & & & 064 \\
\hline & & $ه$ & $ه$ & $ه$ & 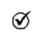 & 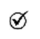 & $ه$ & $ه$ & 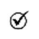 & $ه$ & $ه$ & $ه$ & $\otimes$ & 0 & $ه$ & $\varnothing$ & 0 & 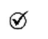 & 0 & 0.04 \\
\hline 11 & $\omega B 97 X-D / 6-311 G(d)-$ UF & & & & & ut 0 & & & & & & & & & ut 0 & & & & & 044 \\
\hline II & grid - QHA Truhlar & $\varnothing$ & ه & $ه$ & $\varnothing$ & $ه$ & $\varnothing$ & $ه$ & $ه$ & $\varnothing$ & $\varnothing$ & $ه$ & $\varnothing$ & $\varnothing$ & $\varnothing$ & 0 & $ه$ & $\varnothing$ & $\varnothing$ & 0.44 \\
\hline 12 & $\omega B 97 X-D / 6-311 G(d)-$ UF & & & & & ut o & & & & & & & & & ut o & & & & & 048 \\
\hline 12 & grid - QHA Grimme & $ه$ & $ه$ & ه & $\varnothing$ & $\theta$ & 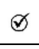 & $ه$ & 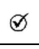 & ه & $\varnothing$ & $\varnothing$ & $\varnothing$ & $\varnothing$ & $\theta$ & $ه$ & $\varnothing$ & $\varnothing$ & $\varnothing$ & 0.40 \\
\hline & & & & & & ut o & & & & & & & & & ut o & & & & & \\
\hline 13 & wB9/X-D/6-311G(d,p) & $\theta$ & $ه$ & $ه$ & $ه$ & $ه$ & $ه$ & $ه$ & $ه$ & $ه$ & 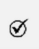 & 0 & $ه$ & 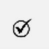 & 0 & O & $ه$ & $ه$ & $\varnothing$ & 1.06 \\
\hline 14 & $\omega B 97 X-D / 6-311 G(d, p)$ QHA & & & & & ut o & & & & & & & & & ut o & & & & & \\
\hline 14 & Truhlar & $ه$ & $ه$ & $ه$ & $\varnothing$ & 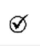 & $ه$ & $ه$ & $\varnothing$ & $ه$ & $\varnothing$ & $\varnothing$ & $\otimes$ & $ه$ & O & O & $\varnothing$ & $ه$ & $\varnothing$ & 0.70 \\
\hline 15 & $\omega B 97 X-D / 6-311 G(d, p)$ QHA & & & & & ut o & & & & & & & & & ut o & & & & & \\
\hline 10 & Grimme & $\varnothing$ & $\varnothing$ & $\varnothing$ & $\varnothing$ & $\varnothing$ & ه & $\varnothing$ & $\varnothing$ & $ه$ & $ه$ & $\varnothing$ & $\varnothing$ & $\varnothing$ & 0 & O & $\varnothing$ & $\varnothing$ & $\varnothing$ & 0.83 \\
\hline 16 & $\omega B 97 X-D / 6-311 G(d, p)-U F$ & & & & & ut 0 & & & & & & & & & ut 0 & & & & & \\
\hline 10 & grid & $\varnothing$ & 0 & 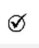 & $\varnothing$ & ه & $ه$ & ه & $\varnothing$ & $\varnothing$ & $\varnothing$ & 0 & 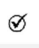 & 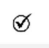 & 0 & $\theta$ & 0 & 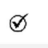 & $\theta$ & 0.77 \\
\hline 17 & $\omega B 97 X-D / 6-311 G(d, p)-U F$ & & & & & ut 0 & & & & & & & & & ut 0 & & & & & \\
\hline 11 & grid - QHA Truhlar & $ه$ & 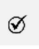 & $\varnothing$ & d & ه & $ه$ & $ه$ & 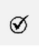 & $ه$ & $ه$ & $ه$ & $ه$ & $\theta$ & 0 & ه & $ه$ & 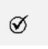 & $\varnothing$ & 0.57 \\
\hline 18 & $\omega B 97 X-D / 6-311 G(d, p)-U F$ & & & & & ut o & & & & & & & & & ut 0 & & & & & \\
\hline 10 & grid - QHA Grimme & ه & $ه$ & $\varnothing$ & 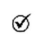 & $\varnothing$ & $ه$ & $ه$ & $\varnothing$ & $ه$ & $\varnothing$ & $ه$ & $\otimes$ & $\varnothing$ & 0 & $ه$ & 0 & $ه$ & $ه$ & 0.63 \\
\hline
\end{tabular}

[a] Each circle (" $\varnothing$ " or " $\bigcirc$ ") corresponds to a substrate shown in the representations above the table, following the order in which they are displayed. " $\sigma$ " = positive result in a specific substrate; "O" $=$ negative result in a specific substrate. [b] Compared to experimental $\Delta \Delta G^{\ddagger}$ values and only valid when the correct absolute configuration is calculated. See the ESI for all the $\Delta \Delta \mathrm{G}^{\ddagger}$ and error values. $\Delta \Delta \mathrm{G}^{\ddagger}$ is the difference of $\mathrm{G}$ between the TS1 of pathways $\mathbf{P 1}$ and $\mathbf{P} 3$. 
After this study, different types of basis sets were explored in combination with $\omega B 97 X-D$ in order to find a computational approach that calculated the correct absolute configuration of the products with $\Delta \Delta G^{\ddagger}$ errors in the calculated enantioselectivities within $1 \mathrm{kcal} / \mathrm{mol}$ in the majority of the nine reactions. Different double zeta (Def2-SVP, 6-31G(d,p), 6$\left.31+G(d),{ }^{[27]} 6-31++G(d, p)\right)$ as well as triple zeta $(6-311 G(d), 6-$ $311 G(d, p), \quad 6-311++G(d, p), \quad 6-311+G(d), \quad T Z V P^{[28]}$ and Def2TZVP) basis sets were tested using 4-chlorobenzaldehyde (1d) (Table 9), since in this example the opposite absolute configuration was observed for most of the computational approaches tested before. Def2SVP and $6-31 G(d, p)$ were discarded because they led to the undesired absolute configuration (Table 9, entries 1 and 7). On the contrary, when diffuse functions were added to the $6-31 \mathrm{G}$ basis set $(6-31+G(d))$ or triple zeta basis sets were used, the correct enantioselectivity was calculated (Table 9, entries $2-5$ and 8 ). The $6-311++G(d, p)$ and Def2TZVP basis sets were discarded because their computation times are significantly longer than the times required for other basis sets (Table 9, entries 6 and 9 ).

Table 9. $\Delta \Delta \mathrm{G}^{\ddagger}$ and errors $(\mathrm{kcal} / \mathrm{mol})$ of the Henry reaction with 4chlorobenzaldehyde (1d) using $\omega B 97 X-D$ with different basis sets.

\begin{tabular}{cclc}
\hline Entry & Basis set & $\Delta \Delta \mathrm{G}^{\ddagger}$ & Error \\
\hline 1 & $6-31 \mathrm{G}(\mathrm{d}, \mathrm{p})$ & $0.49^{[\mathrm{b}]}$ & 1.28 \\
2 & $6-31+\mathrm{G}(\mathrm{d})$ & -2.22 & -1.43 \\
3 & $6-311 \mathrm{G}(\mathrm{d})$ & -2.17 & -1.38 \\
4 & $6-311 \mathrm{G}(\mathrm{d}, \mathrm{p})$ & -1.20 & -0.41 \\
5 & $6-311+\mathrm{G}(\mathrm{d})$ & -1.75 & -0.96 \\
6 & $6-311++\mathrm{G}(\mathrm{d}, \mathrm{p})$ & n.d..$^{[\mathrm{a}]}$ & - \\
7 & Def2SVP & $0.68^{[\mathrm{b}]}$ & 1.47 \\
8 & TZVP & -3.17 & -2.38 \\
9 & Def2TZVP & n.d..$^{[a]}$ & - \\
10 & Experimental & -0.79 & 0 \\
\hline
\end{tabular}

[a] n.d.: not determined. The relatively long computational times required for the studies that employed these basis sets made their use unpractical compared to the times required when using other basis sets. [b] Positive $\Delta \Delta \mathrm{G}^{\ddagger}$ values are represented in red and correspond to calculations that led to the opposite absolute configuration of the product compared to experimental results. $\Delta \Delta G^{\ddagger}$ is the difference of $G$ between the TS1 of pathways $\mathbf{P} 1$ and $\mathbf{P} 3$.

We continued the studies using Pople's 6-311G(d) and 6$311 \mathrm{G}(\mathrm{d}, \mathrm{p})$ basis sets, since they showed much shorter computational times in comparison with the other basis sets that showed the correct absolute configuration of the product in the reaction with 4-chlorobenzaldehyde (1d) (TZVP, Def2TZVP and basis sets with diffuse functions). When using the 6-311G(d) basis set, the correct absolute configuration was calculated in all of the reactions and the MAEs were similar when compared to the results obtained with the approaches based on the wB97X$\mathrm{D} / 6-31 \mathrm{G}(\mathrm{d})$ combination (Table 8, entries 7-12). Even though 6$311 \mathrm{G}(\mathrm{d}, \mathrm{p})$ is a larger basis set than $6-311 \mathrm{G}(\mathrm{d})$, it led to worse results and required more computation time (Table 8 , entries 1318). UF grids and QHAs were also tested with the 6-311G(d) and $6-311 G(d, p)$ basis sets and the results showed once again that these modifications contribute in a great extent to achieving more precise results in the majority of the cases. This is especially relevant in the case of QHAs, since these corrections are rarely used in organocatalysis even though the systems studied in this area normally have many low-lying vibrational modes that are potential sources of error in the calculated results. ${ }^{[29]}$

The results of the computational screening of substrates showed that method $\omega B 97 X-D / 6-311 G(d)$ with QHAs and UF grid is the most reliable approach for studying computationally these systems (Table 8 , entries 11 and 12). This method provides accurate results even in relatively large systems that contain around 100 atoms and include various types of non-covalent interactions. In most cases, the results of the nine reactions are within an absolute error margin of only $1 \mathrm{kcal} / \mathrm{mol}$. The use of 6 $311 \mathrm{G}(\mathrm{d})$ also saves a large amount of time when compared to the calculation times required by larger triple-zeta basis sets employed in other organocatalytic studies, such as the TZV and Def2TZV basis set families.

\section{Conclusions}

This is the first study where the accuracy and computational cost of different computational approaches have been tested in squaramide catalysis. This Henry reaction represents a complex catalytic system of about 100 atoms with a significant number of non-covalent interactions. Different computational methodologies were tested in order to find an accurate approach that required the least possible amount of calculation time.

Initial experimental tests showed that catalyst $\mathbf{3}$ formed weak interactions with aldehyde $\mathbf{1 a}$ as well as suggested that the amino group of 3 deprotonates a molecule of $\mathrm{MeNO}_{2}$. In addition, it was observed that retro-Henry reactions could proceed but they are considerably slower than the corresponding Henry reactions. Furthermore, NMR studies determined that the orders of reaction of $\mathbf{3}$ and $\mathbf{1 a}$ are both 1 . These studies were also employed to determine KIEs and the secondary inverse KIE observed in this reaction proposed that the rate-limiting reaction step is the nitronate attack on the aldehydes (represented as step TS1). Moreover, the experimental results of the reactions catalyzed by $\mathbf{5}$ showed that the $\mathrm{OH}$ group of catalyst $\mathbf{3}$ was not involved in the mechanism. Finally, different experiments were carried out to discard that water molecules played important roles in the reaction mechanism.

Also, we performed a preliminary computational study to explore: (1) all the possible modes of interaction between catalyst and substrates and (2) which of these catalyst-substrate complexes led to Henry reaction products 4 . The initial experimental and computational results suggested that there were seven different reaction pathways, $\mathbf{P} \mathbf{1}$ to $\mathbf{P 7}$, that conduced to Henry reactions. $\mathbf{P} \mathbf{1}$ and $\mathbf{P} \mathbf{3}$ were the most favorable reaction pathways and the $\Delta \Delta G^{\neq}$of the different reactions were calculated using only the Gibbs free energies of these two pathways. Using only these two pathways for the studies saves time and leads to practically identical results compared to those obtained using the seven pathways.

The effectivity calculating enantiomeric excesses of different combinations of functionals and basis sets was tested using a screening of nine aldehydes with diverse structural features. The results of the screening changed in a great extent depending on the functional employed when the basis sets $6-31 \mathrm{G}(\mathrm{d})$ was used. First, B3LYP and M06-2X led to the wrong absolute configuration of the products in most of the aldehydes studied. Furthermore, B3LYP-D3 was not a precise method for studying these systems either, since there were some reactions that did not show the TS1 in pathway P1, even when larger Pople's basis sets were employed. On the contrary, wB97X-D performed reasonably well considering that $6-31 \mathrm{G}(\mathrm{d})$ is a relatively small basis set. 
After this study, other types of basis sets were tested with WB97X-D in order to discover a more efficient and versatile approach, since the combination $\omega B 97 X-D / 6-31 G(d)$ did not calculate the correct absolute configuration in various products. Different double-zeta and triple-zeta basis sets were tested and the best results were obtained with the $\omega B 97 X-D / 6-311 G(d)$ combination when used with QHAs and UF grids. These approaches lead to precise calculated $\Delta \Delta G^{\ddagger}$ values with error margins lower than $1 \mathrm{kcal} / \mathrm{mol}$ in most of the nine aldehydes employed in the screening, which also supports the mechanism that we proposed for the Henry reaction catalyzed by squaramide 3 .

It is worth noting that the results improved in a great extent when QHAs (either Truhlar's or Grimme's QHA) were included. These corrections normally avoid potential sources of error related to low-lying modes in relatively large systems. The results obtained stress the importance of the introduction of QHAs in this kind of study, especially since they are rarely used in organocatalysis.

This research represents a pivotal starting point for further computational studies using squaramides as organocatalysts and further computation mechanistic studies are currently ongoing in our lab.

\section{Experimental Section}

\section{Experimental Details}

${ }^{1} \mathrm{H}$-NMR spectra were recorded at $300 \mathrm{MHz} . \mathrm{CD}_{3} \mathrm{CN}$ and $\mathrm{CD}_{3} \mathrm{NO}_{2}$ were used as the deuterated solvents. Chemical shifts were reported in the $\delta$ scale relative to residual $\mathrm{CD}_{3} \mathrm{CN}(1.94 \mathrm{ppm})$ and $\mathrm{CD}_{3} \mathrm{NO}_{2}(4.33 \mathrm{ppm})$ for ${ }^{1} \mathrm{H}-\mathrm{NMR}$.

\section{General Method for Measuring Orders of Reaction}

$2.5 \mathrm{~mol} \%$ of catalyst: catalyst $3(0.0025 \mathrm{mmol})$ was dissolved in $0.5 \mathrm{~mL}$ of a mixture $\mathrm{CH}_{3} \mathrm{NO}_{2}: \mathrm{CD}_{3} \mathrm{NO}_{2}$ (95:5) inside a NMR tube. The solution stayed at $30.9{ }^{\circ} \mathrm{C}$ for 10 minutes inside the NMR device. Temperature was measured using a solution of $80 \%$ glycol in DMSO- $d_{6}$ (provided by Bruker). Then, the tube was taken out of the NMR device and aldehyde 1a $(0.1 \mathrm{mmol})$ was quickly added in one portion, mixed vigorously and introduced into the NMR device to start the measurements.

$1 \mathrm{~mol} \%$ of catalyst: catalyst $3(0.0025 \mathrm{mmol})$ was dissolved in $1.25 \mathrm{~mL}$ of a mixture $\mathrm{CH}_{3} \mathrm{NO}_{2}: \mathrm{CD}_{3} \mathrm{NO}_{2}$ (95:5) inside a vial. Then, $0.5 \mathrm{~mL}$ of this solution were poured into a NMR tube and the process followed the same steps explained above.

\section{General Method for Experimental Henry Reactions}

Aldehyde $1(0.4 \mathrm{mmol})$ was added to a solution of squaramide $3(0.004$ $\mathrm{mmol})$ in $\mathrm{MeNO}_{2}(2 \mathrm{~mL})$ at $30.9^{\circ} \mathrm{C}$. After the reaction time, product 4 was isolated by column chromatography and the enantiomeric excess was measured using HPLC.

\section{Computational Methods}

Diverse combinations of density functional theory (DFT) methods and basis sets were used to optimize the geometries of the stationary points (functionals and basis sets employed are detailed in each case). Vibrational frequency calculations were carried out in order to (1) confirm that the stationary points were either energy minima or transition states and (2) calculate the thermal corrections to Gibbs free energies at 304.05 $\mathrm{K}$. Also, intrinsic reaction coordinate (IRC) calculations ${ }^{[30]}$ were performed to verify that the transition states of the different pathways connected to their corresponding Int1 and Int2. Solvent effects (solvent = nitromethane) were included employing the integral equation formalism variant of the polarizable continuum model (IEF-PCM) ${ }^{[31]}$ using the SMD. ${ }^{[8]}$ All the calculations were performed using Gaussian 09 ${ }^{[32}$ installed in the Trueno cluster facility of SGAI-CSIC. The Ultrafine grid was used as implemented in Gaussian 09 [Integral(Grid=UltraFineGrid)] Graphical representations of the structures were created using CYLView $^{[33]}$ and POV-Ray. ${ }^{[34]}$

Quasi-harmonic approximations (QHAs) were calculated from Gaussian frequency calculations using the script created by Dr. Robert Paton and Ignacio Funes-Ardoiz. ${ }^{[26 a]}$ Two QHA versions are used: one developed by Truhlar $^{[26 b]}$ and col. and the other by Grimme. ${ }^{[26 c]}$ In both cases, the frequency cut-off was $100 \mathrm{~cm}^{-1}$.

\section{Acknowledgements}

We thank the Government of Aragon DGA (Research Group E104) for financial support of our research. All the calculations were performed in the Trueno cluster facility of SGAI-CSIC. J. V. A.-R. thanks the DGA for a predoctoral contract. Authors thank Leah C. Weatherman for her help during the text editing process. J. V. A.-R. thanks Dr. Robert S. Paton (CRL, University of Oxford) for his support with the QHA script.

Keywords: computational • mechanism - Henry reaction • squaramide $\bullet$ trifunctional

[1] a) A. Berkessel, H. Gröger, Asymmetric Organocatalysis: From Biomimetic Concepts to Applications in Asymmetric Synthesis. Wiley$\mathrm{VCH}$ Verlag GmbH: Weinheim, 2005; b) Enantioselective Organocatalysis: Reactions and Experimental Procedures. P. I. Dalko (Ed.), Wiley-VCH Verlag GmbH: Weinheim, 2007; c) Comprehensive Enantioselective Organocatalysis. P. I. Dalko (Ed.), Wiley-VCH Verlag GmbH: Weinheim, 2013

[2] For the pioneering example of squaramide catalysis, see: a) J. P Malerich, K. Hagihara, V. H. Rawal, J. Am. Chem. Soc. 2008, 130 14416-14417. For some reviews, see: b) R. I. Storer, C. Aciro, L. H Jones, Chem. Soc. Rev. 2011, 40, 2330-2346; c) J. Alemán, A. Parra H. Jiang, K. A. Jørgensen, Chem. Eur. J. 2011, 17, 6890-6899; d) M. Tsakos, C. G. Kokotos, Tetrahedron 2013, 69, 10199-10222; e) J. V. Alegre-Requena, Synlett 2014, 25, 298-299; f) P. Chauhan, S. Mahajan, U. Kaya, D. Hack, D. Enders, Adv. Synth. Catal. 2015, 357, 253-281. For some previous computational studies regarding squaramides, see g) T. Lu, S. E. Wheeler, Chem. Eur. J. 2013, 19, 15141-15147; h) J. I. Martínez, L. Villar, U. Uria, L. Carrillo, E. Reyes, J. L. Vicario, Adv. Synth. Catal. 2014, 356, 3627-3648; i) B. Kótai, G. Kardos, A. Hamza, V. Farkas, I. Pápai, T. Soós, Chem. Eur. J. 2014, 20, 5631-5639.

[3] For a relevant example in which rotamers of squaramides were studied, see: M. C. Rotger, M. N. Piña, A. Frontera, G. Martorell, P. Ballester, P M. Deyà, A. Costa, J. Org. Chem. 2004, 69, 2302-2308.

[4] a) F. Liu, Chirality 2013, 25, 675-683; b) R. Kenny, F. Liu, Eur. J. Org Chem. 2015, 5304-5319; c) R. Kenny, F. Liu, Chem. Rec. 2017, 17 535-553.

[5] F. Giacalone, M. Gruttadauria, P. Agrigento, R. Noto, Chem. Soc. Rev 2012, 41, 2406-2447.

[6] J. V. Alegre-Requena, E. Marqués-López, R. P. Herrera, Adv. Synth Catal. 2016, 358, 1801-1809. Highlighted in Synfacts 2016, 12, 743.

[7] Chemical Kinetics and Reaction Mechanisms. J. H. Espenson (Ed.) McGraw-Hill: New York, 1981.

[8] A. V. Marenich, C. J. Cramer, D. G. Truhlar, J. Phys. Chem. B 2009 113, 6378-6396.

[9] C. R. L. Henry, Hebd. Séances Acad. Sci. 1895, 120, 1265-1268.

[10] a) C. Palomo, M. Oiarbide, A. Mielgo, Angew. Chem. Int. Ed. 2004, 43, 5442-5444; Angew. Chem. 2004, 116, 5558-5560; b) C. Palomo, M Oiarbide, A. Laso, Eur. J. Org. Chem. 2007, 2561-2574; c) Y. AlvarezCasao, E. Marqués-López, R. P. Herrera, Symmetry 2011, 3, 220-245. 
[11] For an example involving nitronates, see: K. A. Kurtz, P. F. Fitzpatrick, J. Am. Chem. Soc. 1997, 119, 1155-1156.

[12] a) A. D. Becke, J. Chem. Phys. 1993, 98, 5648-5652; b) C. Lee, W. Yang, R. G. Parr, Phys. Rev. B 1988, 37, 785-789; c) S. H. Vosko, L. Wilk, M. Nusair, Can. J. Phys. 1980, 58, 1200-1211; d) P. J. Stephens, F. J. Devlin, C. F. Chabalowski, M. J. Frisch, J. Phys. Chem. 1994, 98 11623-11627.

[13] a) W. J. Hehre, R. Ditchfield, J. A. Pople, J. Chem. Phys. 1972, 56, 2257-2261; b) P. C. Hariharan, J. A. Pople, Theoret. Chim. Acta 1973 28, 213-222; c) M. M. Francl, W. J. Pietro, W. J. Hehre, J. S. Binkley, M. S. Gordon, D. J. DeFrees, J. A. Pople, J. Chem. Phys. 1982, 77, 3654 3665; d) V. A. Rassolov, M. A. Ratner, J. A. Pople, P. C. Redfern, L. A Curtiss, J. Comp. Chem. 2001, 22, 976-984.

[14] a) A. D. Becke, J. Chem. Phys. 1997, 107, 8554-8560; b) J.-D. Chai, M. Head-Gordon, Phys. Chem. Chem. Phys. 2008, 10, 6615-6620.

[15] a) P. Hobza, J. Šponer, T. Reschel, J. Comp. Chem. 1995, 16, 13151325; b) S. Tsuzuki, H. P. Lüthi, J. Chem. Phys. 2001, 114, 3949-3957; c) E. R. Johnson, R. A. Wolkow, G. A. DiLabio, Chem. Phys. Lett. 2004, 394, 334-338.

[16] Y. Zhao, D. G. Truhlar, Theor. Chem. Acc. 2008, 120, 215-241.

[17] a) S. Grimme, J. Antony, S. Ehrlich, H. Krieg, J. Chem. Phys. 2010, 132, 154104; doi: 10.1063/1.3382344; b) S. Grimme, S. Ehrlich, I. Goerigk, J. Comput. Chem. 2011, 32, 1456-1465.

[18] For examples where the performance of different methods was tested in other organocatalytic reactions, see: a) S. T. Schneebeli, M. L. Hall, R. Breslow, R. Friesner, J. Am. Chem. Soc. 2009, 131, 3965-3973; b) Q. Peng, F. Duarte, R. S. Paton, Chem. Soc. Rev. 2016, 45, 6093-6107. For examples of methods previously used in computational organocatalysis that led to accurate results, see: c) Y.-h. Lam, M. N. Grayson, M. C. Holland, A. Simon, K. N. Houk, Acc. Chem. Res. 2016 49, 750-762.

[19] For an extensive study where single-point corrections on smaller basisset optimizations showed accurate results, see: L. Simón, J. M Goodman, Org. Biomol. Chem. 2011, 9, 689-700.

[20] a) R. Krishnan, J. S. Binkley, R. Seeger, J. A. Pople, J. Chem. Phys. 1980, 72, 650-654; b) A. D. McLean, G. S. Chandler, J. Chem. Phys. 1980, 72, 5639-5648; c) L. A. Curtiss, M. P. McGrath, J.-P. Blaudeau, N E. Davis, R. C. Binning, L. Radom, J. Chem. Phys. 1995, 103, 61046113.

[21] F. Weigend, R. Ahlrichs, Phys. Chem. Chem. Phys. 2005, 7, 3297-3305.

[22] a) T. H. Dunning, Jr. J. Chem. Phys. 1989, 90, 1007-1023; b) D. E. Woon, T. H. Dunning, Jr. J. Chem. Phys. 1993, 98, 1358-1371.

[23] R. Sure, S. Grimme, J. Chem. Theory Comput. 2015, 11, 3785-3801.

[24] a) R. B. McClurg, R. C. Flagan, W. A. Goddard, J. Chem. Phys. 1997, 106, 6675-6680; b) P. Y. Ayala, H. B. Schlegel, J. Chem. Phys. 1998 108, 2314-2325; c) R. B. McClurg, J. Chem. Phys. 1999, 111, 71637164.

[25] S. F. Boys, F. Bernardi, Mol. Phys. 1970, 19, 553-566.

[26] For the script employed to apply the QHAs: a) I. Funes-Ardoiz, R. S. Paton, 2016, GoodVibes v1.0.1, http://doi.org/10.5281/zenodo.60811. For the QHAs theoretical basis: b) R. F. Ribeiro, A. V. Marenich, C. J. Cramer, D. G. Truhlar, J. Phys. Chem. B 2011, 115, 14556-14562; c) S Grimme, Chem. Eur. J. 2012, 18, 9955-9964.

[27] T. Clark, J. Chandrasekhar, G. W. Spitznagel, P. v. R. Schleyer, J. Comput. Chem. 1983, 4, 294-301.

[28] a) A. Schäfer, H. Horn, R. Ahlrichs, J. Chem. Phys. 1992, 97, 2571 2577; b) A. Schäfer, C. Huber, R. Ahlrichs, J. Chem. Phys. 1994, 100 5829-5835.

[29] For previous examples where QHAs were applied in organocatalysis, see: a) S. E. Wheeler, T. J. Seguin, Y. Guan, A. C. Doney, Acc. Chem. Res. 2016, 49, 1061-1069; b) L. Simón, R. S. Paton, J. Org. Chem. 2017, 82, 3855-3863; c) M. N. Grayson, J. Org. Chem. 2017, 82, 43964401.

[30] K. Fukui, Acc. Chem. Res. 1981, 14, 363-368.

[31] J. Tomasi, B. Mennucci, E. Cancès, J. Mol. Struct. (Theochem) 1999, 464, 211-226.

[32] Gaussian 09, Revision D.01, M. J. Frisch, G. W. Trucks, H. B. Schlegel, G. E. Scuseria, M. A. Robb, J. R. Cheeseman, G. Scalmani, V. Barone G. A. Petersson, H. Nakatsuji, X. Li, M. Caricato, A. Marenich, J. Bloino B. G. Janesko, R. Gomperts, B. Mennucci, H. P. Hratchian, J. V. Ortiz A. F. Izmaylov, J. L. Sonnenberg, D. Williams-Young, F. Ding, F.
Lipparini, F. Egidi, J. Goings, B. Peng, A. Petrone, T. Henderson, D. Ranasinghe, V. G. Zakrzewski, J. Gao, N. Rega, G. Zheng, W. Liang, M. Hada, M. Ehara, K. Toyota, R. Fukuda, J. Hasegawa, M. Ishida, T. Nakajima, Y. Honda, O. Kitao, H. Nakai, T. Vreven, K. Throssell, J. A Montgomery, Jr., J. E. Peralta, F. Ogliaro, M. Bearpark, J. J. Heyd, E. Brothers, K. N. Kudin, V. N. Staroverov, T. Keith, R. Kobayashi, J. Normand, K. Raghavachari, A. Rendell, J. C. Burant, S. S. Iyengar, J. Tomasi, M. Cossi, J. M. Millam, M. Klene, C. Adamo, R. Cammi, J. W Ochterski, R. L. Martin, K. Morokuma, O. Farkas, J. B. Foresman, D. J. Fox, Gaussian, Inc., Wallingford CT, 2016.

[33] CYLview, 1.0b; C. Y. Legault, Université de Sherbrooke, 2009 (http://www.cylview.org).

[34] POV-Ray version 3.6. Persistence of Vision Pty. Ltd. (2004). Persistence of Vision (TM) Raytracer. Persistence of Vision Pty. Ltd. Williamstown, Victoria, Australia. http://www.povray.org 